\title{
Exhaust Nozzle Plume Effects on Sonic Boom Test Results for Isolated Nozzles
}

Raymond S. Castner

Glenn Research Center, Cleveland, Ohio 


\section{NASA STI Program . . . in Profile}

Since its founding, NASA has been dedicated to the advancement of aeronautics and space science. The NASA Scientific and Technical Information (STI) program plays a key part in helping NASA maintain this important role.

The NASA STI Program operates under the auspices of the Agency Chief Information Officer. It collects, organizes, provides for archiving, and disseminates NASA's STI. The NASA STI program provides access to the NASA Aeronautics and Space Database and its public interface, the NASA Technical Reports Server, thus providing one of the largest collections of aeronautical and space science STI in the world. Results are published in both non-NASA channels and by NASA in the NASA STI Report Series, which includes the following report types:

- TECHNICAL PUBLICATION. Reports of completed research or a major significant phase of research that present the results of NASA programs and include extensive data or theoretical analysis. Includes compilations of significant scientific and technical data and information deemed to be of continuing reference value. NASA counterpart of peer-reviewed formal professional papers but has less stringent limitations on manuscript length and extent of graphic presentations.

- TECHNICAL MEMORANDUM. Scientific and technical findings that are preliminary or of specialized interest, e.g., quick release reports, working papers, and bibliographies that contain minimal annotation. Does not contain extensive analysis.

- CONTRACTOR REPORT. Scientific and technical findings by NASA-sponsored contractors and grantees.
- CONFERENCE PUBLICATION. Collected papers from scientific and technical conferences, symposia, seminars, or other meetings sponsored or cosponsored by NASA.

- SPECIAL PUBLICATION. Scientific, technical, or historical information from NASA programs, projects, and missions, often concerned with subjects having substantial public interest.

- TECHNICAL TRANSLATION. Englishlanguage translations of foreign scientific and technical material pertinent to NASA's mission.

Specialized services also include creating custom thesauri, building customized databases, organizing and publishing research results.

For more information about the NASA STI program, see the following:

- Access the NASA STI program home page at http://www.sti.nasa.gov

- E-mail your question via the Internet to help@ sti.nasa.gov

- Fax your question to the NASA STI Help Desk at $443-757-5803$

- Telephone the NASA STI Help Desk at 443-757-5802

- Write to: NASA Center for AeroSpace Information (CASI) 7115 Standard Drive Hanover, MD 21076-1320 


\section{Exhaust Nozzle Plume Effects on Sonic Boom Test Results for Isolated Nozzles}

Raymond S. Castner

Glenn Research Center, Cleveland, Ohio

Prepared for the

28th Applied Aerodynamics Conference

sponsored by the American Institute of Aeronautics and Astronautics

Chicago, Illinois, June 28-July 1, 2010

National Aeronautics and

Space Administration

Glenn Research Center

Cleveland, Ohio 44135 


\section{Acknowledgments}

The author recognizes the contributions of Allison Ronning, from Wichita State University, who performed significant analysis. In addition, Martin Silverman, John Jones and Warren Holt provided design and fabrication of the wind tunnel model and support systems. Facility support was provided by Scott Smrdel, Bob Clark and Bob McClusky, at the NASA Glenn Research Center. This work was funded by the NASA Fundamental Aeronautics Program, Supersonics Project.

This work was sponsored by the Fundamental Aeronautics Program at the NASA Glenn Research Center.

Level of Review: This material has been technically reviewed by technical management.

Available from

NASA Center for Aerospace Information 7115 Standard Drive

Hanover, MD 21076-1320
National Technical Information Service 5301 Shawnee Road Alexandria, VA 22312

Available electronically at http://www.sti.nasa.gov 


\title{
Exhaust Nozzle Plume Effects on Sonic Boom Test Results for Isolated Nozzles
}

\author{
Raymond S. Castner \\ National Aeronautics and Space Administration \\ Glenn Research Center \\ Cleveland, Ohio 44135
}

\begin{abstract}
Reducing or eliminating the operational restrictions of supersonic aircraft over populated areas has led to extensive research at NASA. Restrictions were due to the disturbance of the sonic boom, caused by the coalescence of shock waves formed off the aircraft. Recent work has been performed to reduce the magnitude of the sonic boom $\mathrm{N}$-wave generated by airplane components with focus on shock waves caused by the exhaust nozzle plume. Previous Computational Fluid Dynamics (CFD) analysis showed how the shock wave formed at the nozzle lip interacts with the nozzle boat-tail expansion wave. An experiment was conducted in the 1- by 1-ft Supersonic Wind Tunnel at the NASA Glenn Research Center to validate the computational study. Results demonstrated how the nozzle lip shock moved with increasing nozzle pressure ratio (NPR) and reduced the nozzle boat-tail expansion, causing a favorable change in the observed pressure signature. Experimental results were presented for comparison to the CFD results. The strong nozzle lip shock at high values of NPR intersected the nozzle boat-tail expansion and suppressed the expansion wave. Based on these results, it may be feasible to reduce the boat-tail expansion for a future supersonic aircraft with under-expanded nozzle exhaust flow by modifying nozzle pressure or nozzle divergent section geometry.
\end{abstract}

\section{Nomenclature}

$\beta \quad$ nozzle boat tail angle, ${ }^{\circ}$

$D \quad$ test nozzle diameter, in.

NPR nozzle pressure ratio $=P_{t} / P_{\infty}$

$P \quad$ local static pressure, psia

$P_{t} \quad$ total pressure in nozzle, psia

$P_{\infty} \quad$ free stream static pressure, psia

$\triangle P / P \quad\left(P-P_{\infty}\right) / P_{\infty}$

$t \quad$ time, sec

$x \quad$ axial distance from jet simulator nosecone tip, in.

$y \quad$ distance from nozzle centerline, in.

\section{Introduction}

NASA has been conducting extensive research programs to reduce the sonic boom signature caused by supersonic flight speeds. Current aircraft flight restrictions, allowing supersonic flight over water only, are due to the disturbance caused by the sonic boom. The sonic boom is generated by coalescing shock waves formed by aircraft components, which generate an $\mathrm{N}$-wave. A sample $\mathrm{N}$-wave sonic boom signature is shown in Figure 1. The N-wave consists of a rise in pressure versus time as the aircraft 'bowwave' passes over an observer, followed by a reduction in pressure, and finally a return to atmospheric pressure. Previous work by NASA, such as the Shaped Sonic Boom Demonstrator (Ref. 1) (SSBD) and the Quiet Spike (Ref. 2) have studied how the sonic boom signature generated by the front of the aircraft can be reduced with aircraft shaping. 


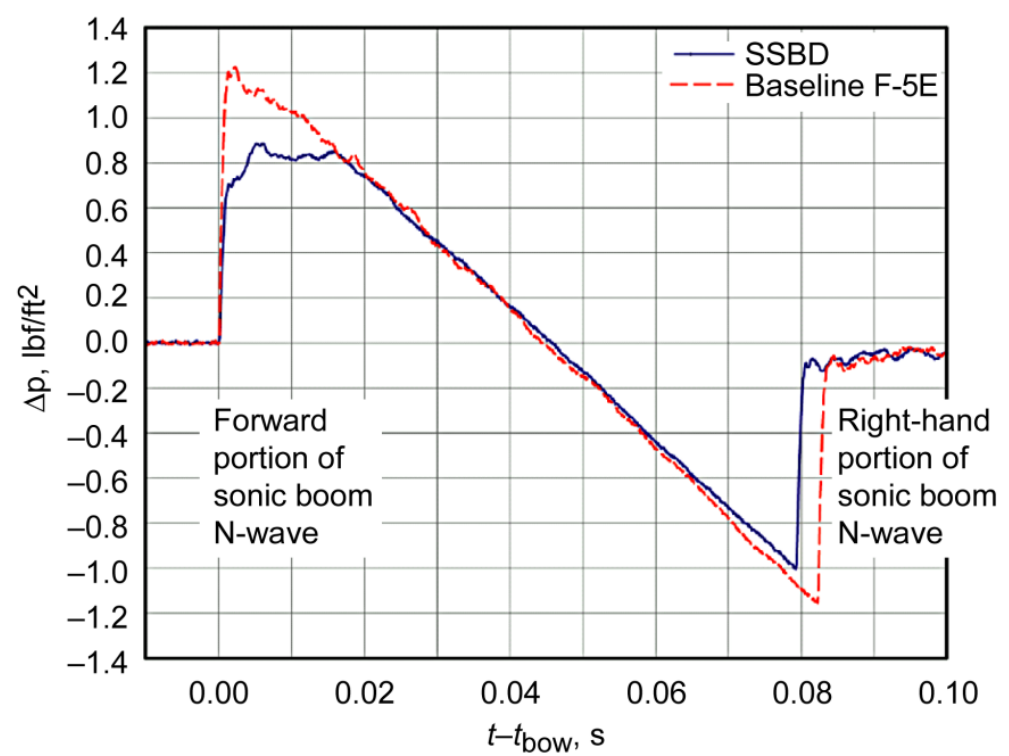

Figure 1.-Ground-level shaped sonic boom recording in blue, baseline F-5E N-Wave in red, SSBD flight 9 (Ref. 1).

Complementary work is desired to reduce the sonic boom signature in the aft portion of the sonic boom N-wave, which in turn would decrease the peak-to-peak magnitude and result in a reduced sonic boom. This can be accomplished by aircraft shaping, and through study of how aft components, such as the tail, nacelles, and nozzles contribute to the right hand portion of the sonic boom N-wave.

Previous work on exhaust nozzle contribution to sonic boom included a report by Putnam and Capone (Ref. 3), and another by Barger and Melson (Ref. 4). In the work by Putnam and Capone, nozzles were tested from a fully expanded Mach 1.7 nozzle to a fully expanded Mach 2.9 nozzle. Their study was conducted in a wind tunnel, where near-field pressure measurements were made at one nozzle diameter away from the model. Wind tunnel conditions were Mach 2.2 at a simulated altitude of 50,000 ft. In 2009, Castner (Ref. 5) revisited this work to use as a baseline for studies on the exhaust nozzle contribution to sonic boom. Near-field pressure signatures from the wind tunnel test were examined, where stronger pressure signatures were observed for high levels of nozzle pressure ratio (NPR). From the Putnam and Capone report, a baseline nozzle was selected for an axisymmetric Computational Fluid Dynamics (CFD) study. During the CFD analysis, it was determined that over-expanded and under-expanded operation of the nozzle had an effect on the $\mathrm{N}$-wave boom signature. The work demonstrated the feasibility of reducing the magnitude of the sonic boom $\mathrm{N}$-wave by controlling the nozzle plume interaction with the nozzle boat-tail flow structure. Under-expanded exhaust nozzle flow had a favorable result on near field pressure signatures, suggesting that the nozzle plume shock location could be controlled through control of nozzle pressure or nozzle divergent section geometry.

Results from the CFD study were used to develop wind tunnel test capability to both validate and predict results obtained for supersonic nozzle concepts. Testing has been performed and comparisons made to the CFD predictions for the baseline nozzle. Post-test analysis has been performed to analyze differences between test data and CFD predictions. The purpose of this report is (1) to present the wind tunnel test results, (2) to make comparisons to the pre-test CFD results, and (3) to make comparisons to post-test CFD analysis. The present work studies the effects of the nozzle exhaust plume and the contribution to the right hand portion of the sonic boom $\mathrm{N}$-wave. Wind tunnel test results include schlieren images of the nozzle exhaust shock structure and near-field static pressure profiles as collected from a static pressure probe. 


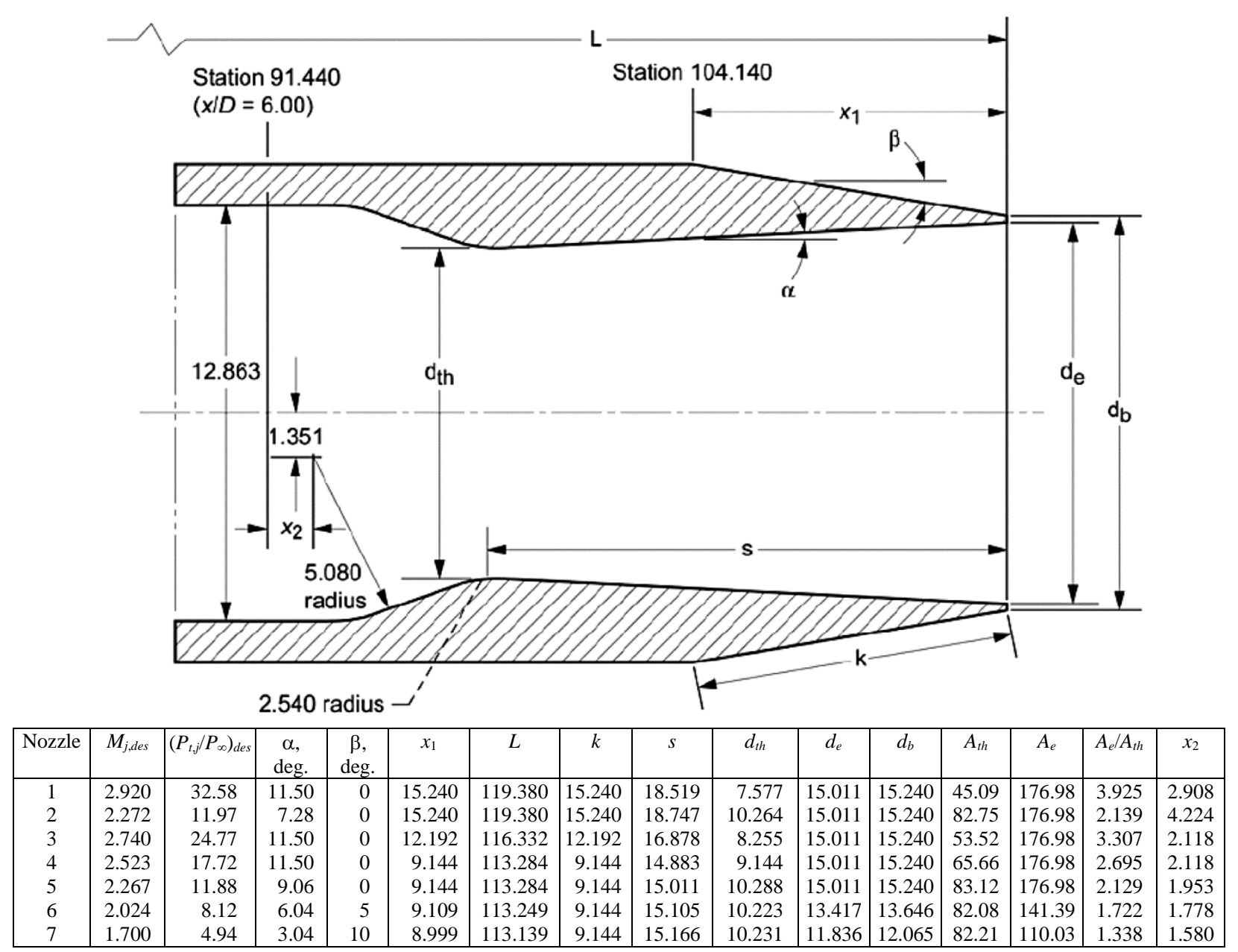

Figure 2.-Baseline Nozzle, from Putnam (Ref. 3).

\section{Background}

A baseline nozzle was developed for testing in the NASA Glenn Research Center (GRC) 1-ft by 1-ft Supersonic Wind Tunnel (Ref. 6). Figure 2 depicts the design of the Mach 2.0 baseline supersonic exhaust nozzle configuration, which was a replica of the Putnam 'Nozzle 6.' Previous computational and wind tunnel tests were performed on this nozzle at flight speeds of Mach 2.2 and an altitude of 50,000 ft. Figure 3 shows the larger scale wind tunnel model used by Putnam and Capone, where an $x / D$ of zero is the tip of the nose cone. Near-field pressure measurements were made at one nozzle diameter above the test nozzle centerline. Data were taken from 'Nozzle 6', with a $5^{\circ}$ boat tail angle, which was digitized from the report and displayed in Figure 4. Previous CFD data were obtained to match the experimental test conditions (Castner (Ref. 5).

Pressure signatures for 'Nozzle 6', plotted as a ratio of $\Delta P / P_{\infty}$, were compared to Putnam's experimental data. The results from the comparison are plotted in Figure 4 for a NPR of 8, which was the design pressure ratio. Agreement between the experiment and the axisymmetric CFD was fair, and displays a reduction in the near-field static pressure caused by the flow expansion off the nozzle boat-tail. The expansion was followed by a shock at the nozzle lip, and then an expansion back to flight conditions. (Note that the near-field pressure distribution is different from an ' $\mathrm{N}$-wave'. With propagation, this disturbance takes the shape of an N-wave, as demonstrated in Figure 5(c)). 


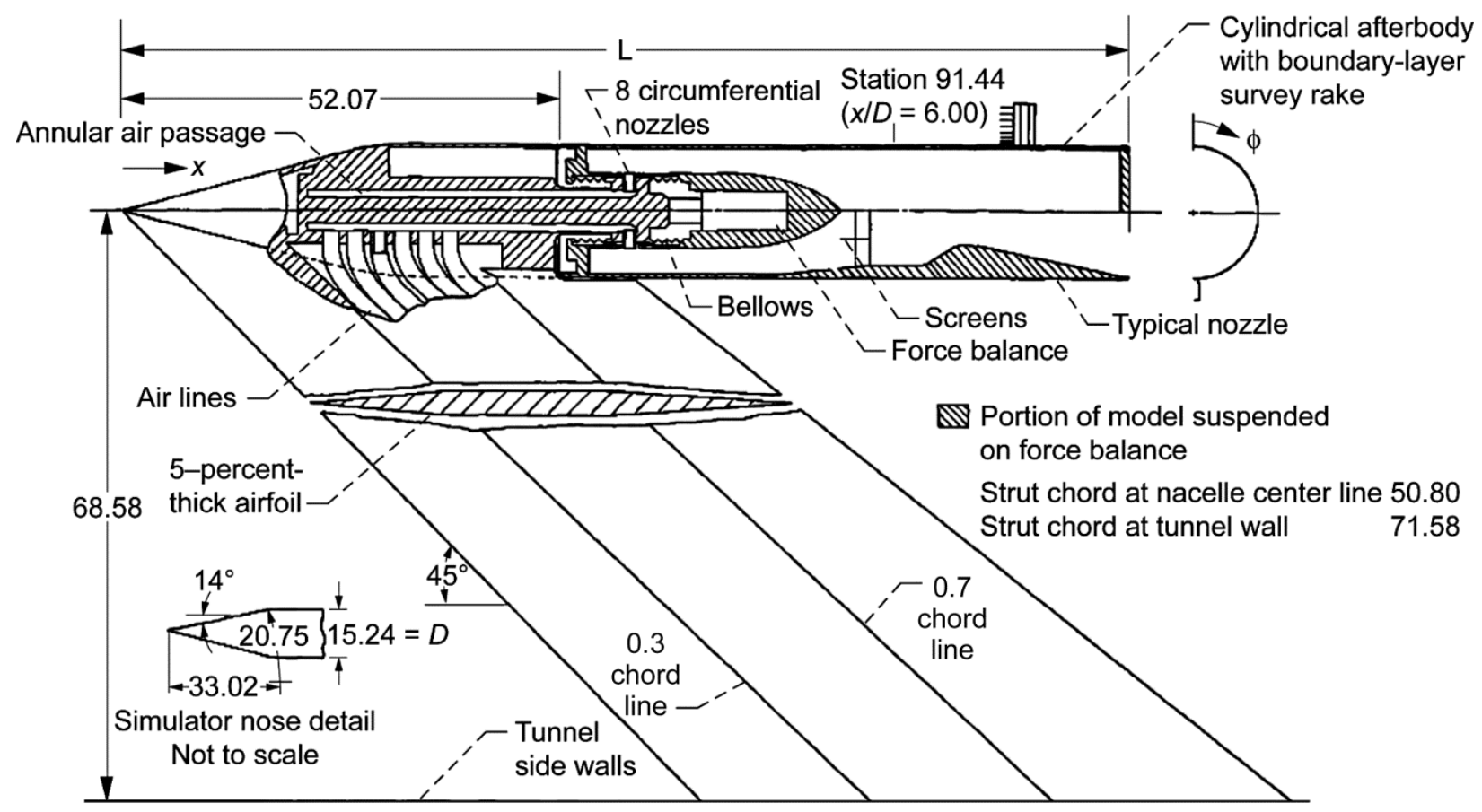

Figure 3.-Exhaust nozzle simulator from Putnam (Ref. 3).

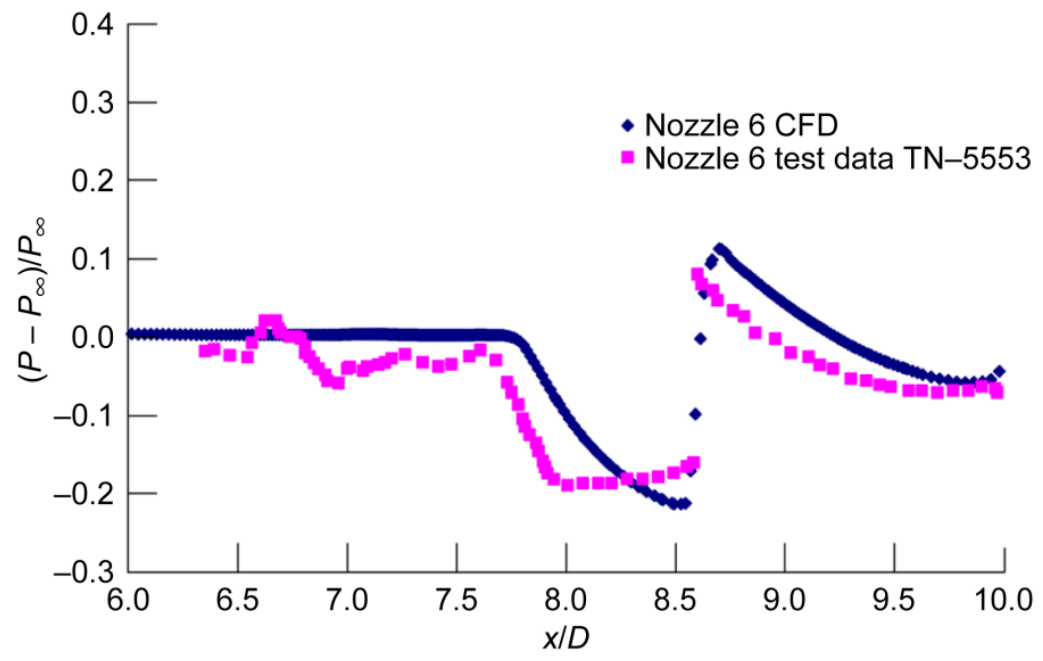

Figure 4.-Near-field pressure profile at 1 nozzle diameter from baseline 'Nozzle 6', NPR of 8.

While NPR of 8 produces fully expanded flow, simulations were also conducted at NPR of 6 and 7 , resulting in over-expanded nozzle flow; and then simulations were conducted at NPR of 9 and 10, resulting in under-expanded nozzle flow. The effects of under-expanded and over-expanded nozzle flow were computed at a distance far from the nozzle, 150 in. away, or 10 nozzle diameters away. Changes in NPR caused changes in the magnitude of the observed pressure signature, which would correspond to a change in the observed sonic boom signature and are shown in Figure 5(a). Locations of the cut planes for the near field and far-field CFD data are shown in Figure 5(b). Finally, Figure 5(c) shows what happens to the far-field pressure signatures when they are propagated to the ground. In Figure 5(c) it is evident that as NPR was increased, the peak-to-peak magnitude for the right hand portion of the pressure signature was decreased. These were results intended for validation in the current experiment, conducted in the GRC 1- by 1-ft Supersonic Wind Tunnel. 

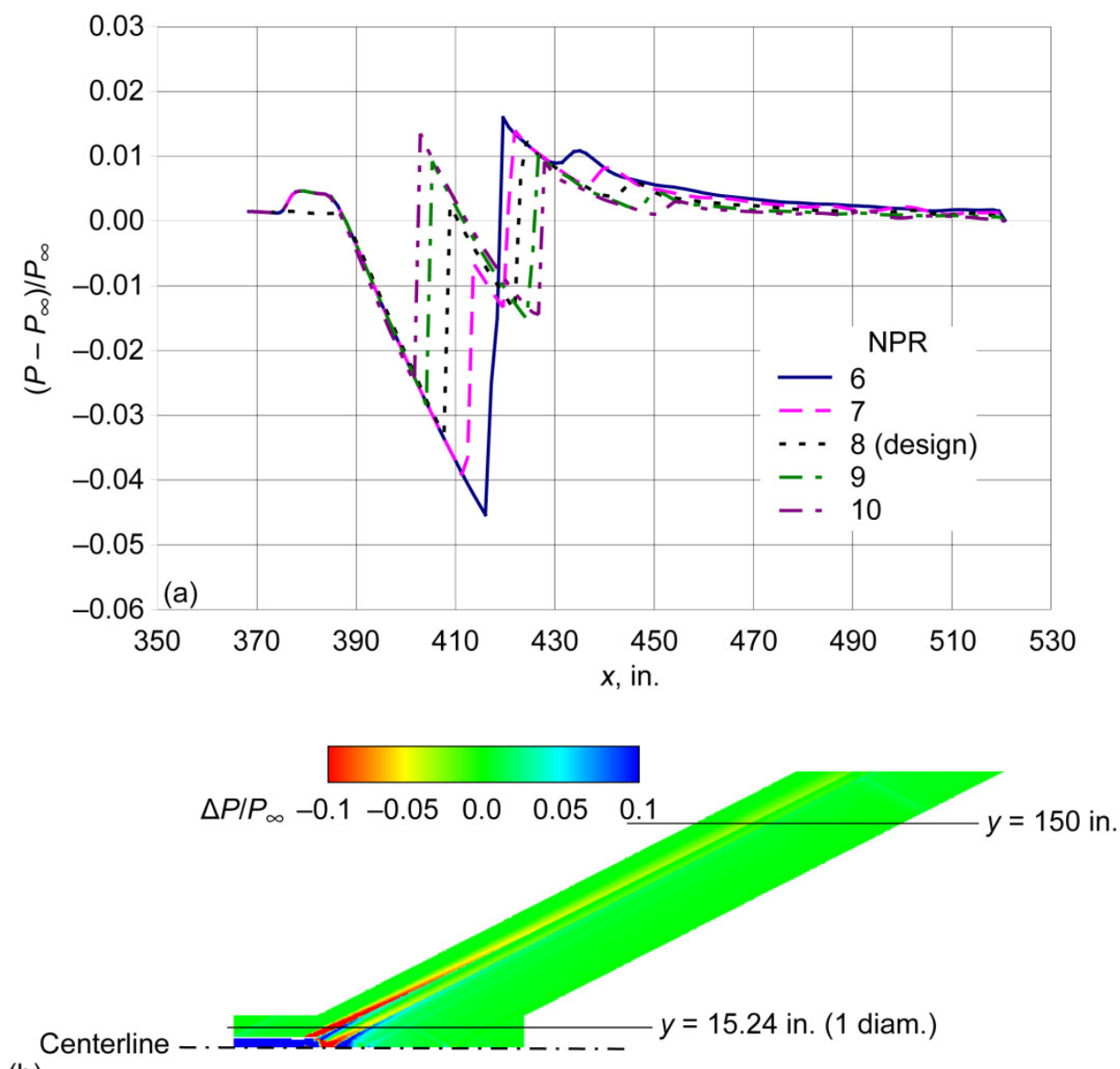

(b)

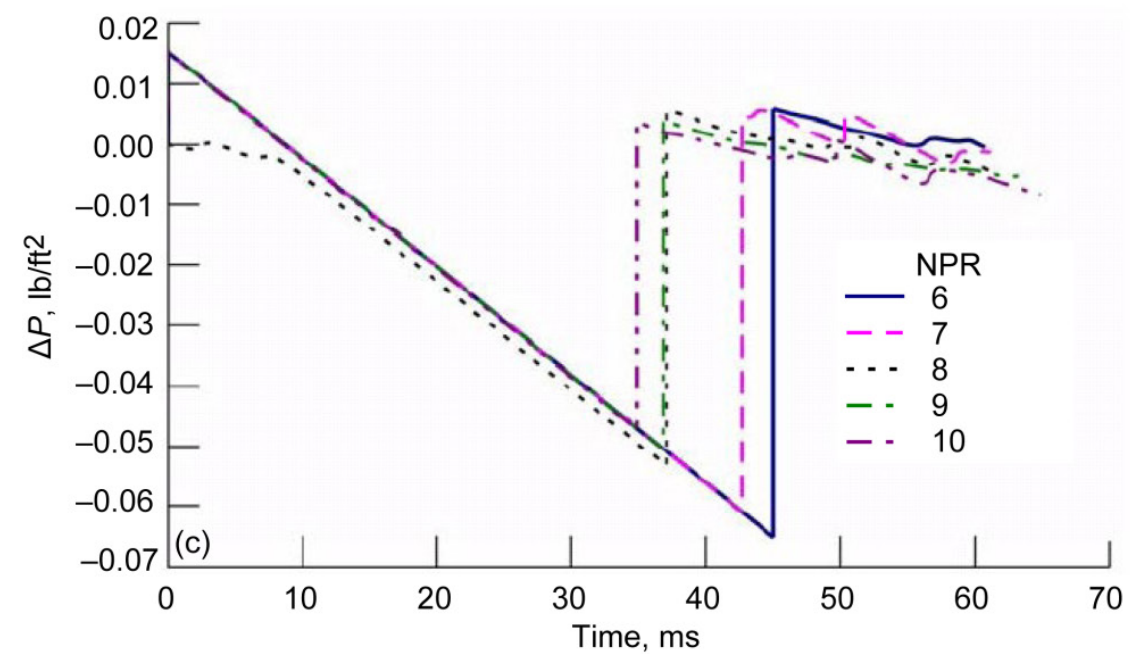

Figure 5.-(a) Far-field pressure profiles $\Delta P / P_{\infty}$ at $y=150$ in from nozzle centerline. Baseline 'Nozzle 6' NPR 6 to 10. (b) Location of cut planes for CFD predictions of $\triangle P / P_{\infty}$. (c) Estimated sonic boom signature at ground through an ideal atmosphere, NPR 6 to 10. 


\section{Test Setup}

The wind tunnel model for the experiment was designed to operate across a variety of wind tunnel Mach numbers, nozzle pressure ratios, and simulated altitudes. Design Mach numbers ranged from 1.4 to 3.0. The range of NPRs were from 6 to 12, and altitudes were from 30,000 ft (4.36 psia) to 50,000 ft (1.68 psia). The actual test nozzle was a replica of Putnam's (Ref. 3) 'Nozzle 6'. This section is to review the wind tunnel model, instrumentation, and model location in the wind tunnel.

\section{Model}

The wind tunnel model consisted of three major parts, the upper plenum, the strut, and the lower plenum, as displayed in Figure 6. A photo of the rig installation is also provided in Figure 7. The upper plenum design was 1-in. outer diameter, and had an overall length from the nosecone to the nozzle exit of 9 in. Both nosecone and nozzle were attached with fine pitched threaded connections. The support strut was $3 / 8$ in. in thickness and contained nine passages to supply airflow. Air supply lines were $1 / 4 \mathrm{in}$. diameter, and the passages supplied 90 psia of pressure to achieve 20 psia at the nozzle inlet for test conditions at 50,000 ft altitude. To accommodate larger nozzles and testing at lower altitudes, the maximum design pressure at the strut was 233 psia, to achieve 52 psia at the nozzle inlet. Choked orifice holes were needed on top of the strut supply lines to obtain required mass flow. Orifice holes were 0.210 in. in diameter. Air was supplied to the bottom of the strut through a lower plenum by the centralized 450 psig pressurized air system at GRC.

The location of the strut and model was designed to move forward and aft in the wind tunnel test section. This was accomplished with a slot, allowing 6 in. of overall travel. In this manner the rig location could be modified to avoid unforeseen wind tunnel flow effects or shock wave reflections. Manual changes to rig location could only be made between tests with the wind tunnel turned off.

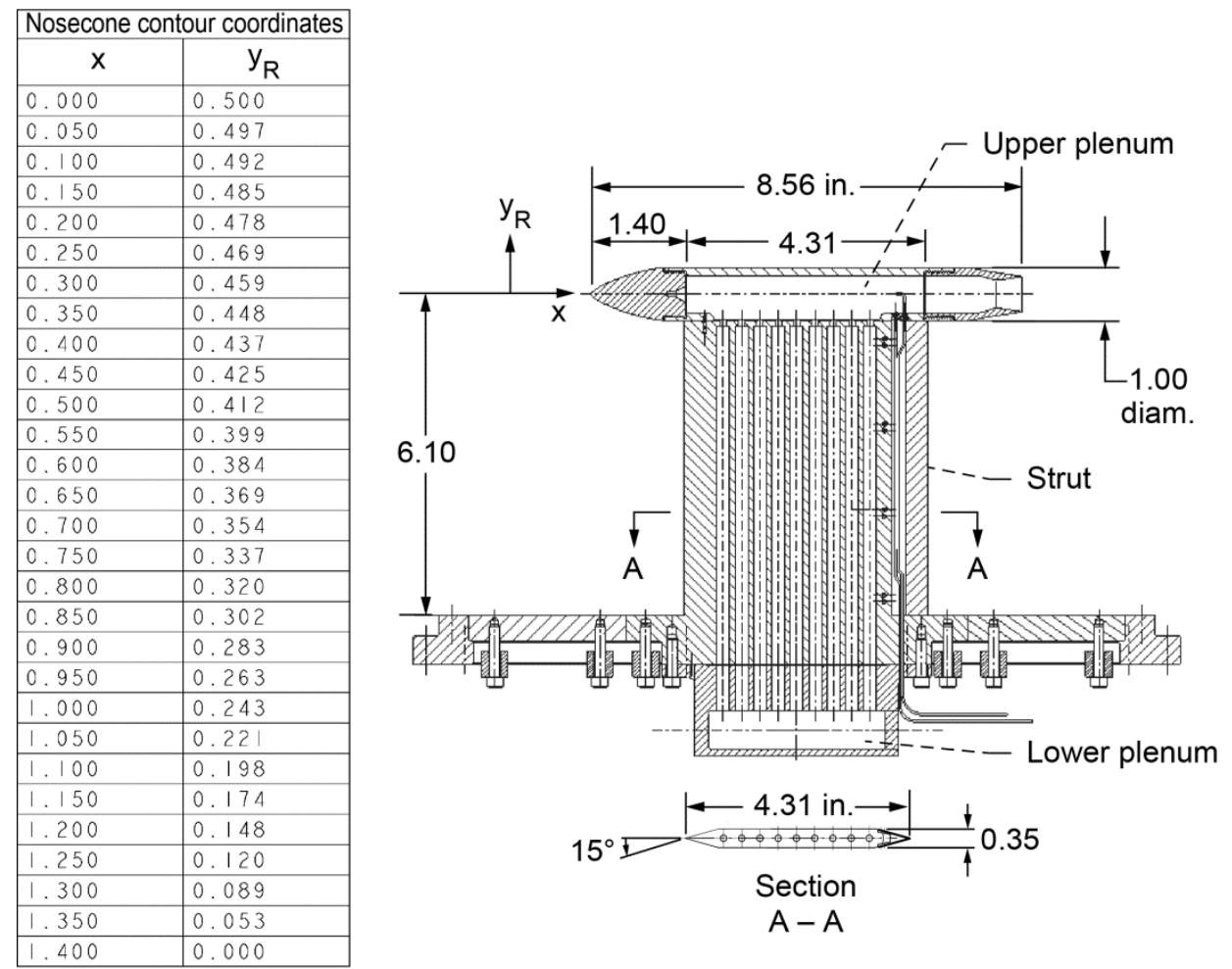

Figure 6.-Wind tunnel model cut-away. 


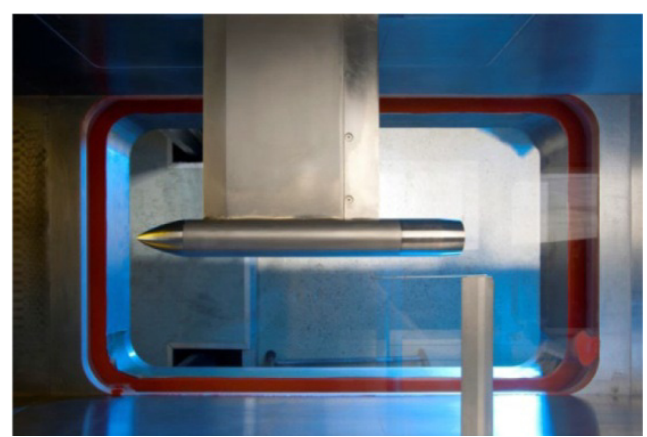

Figure 7.—Wind tunnel model—side view.

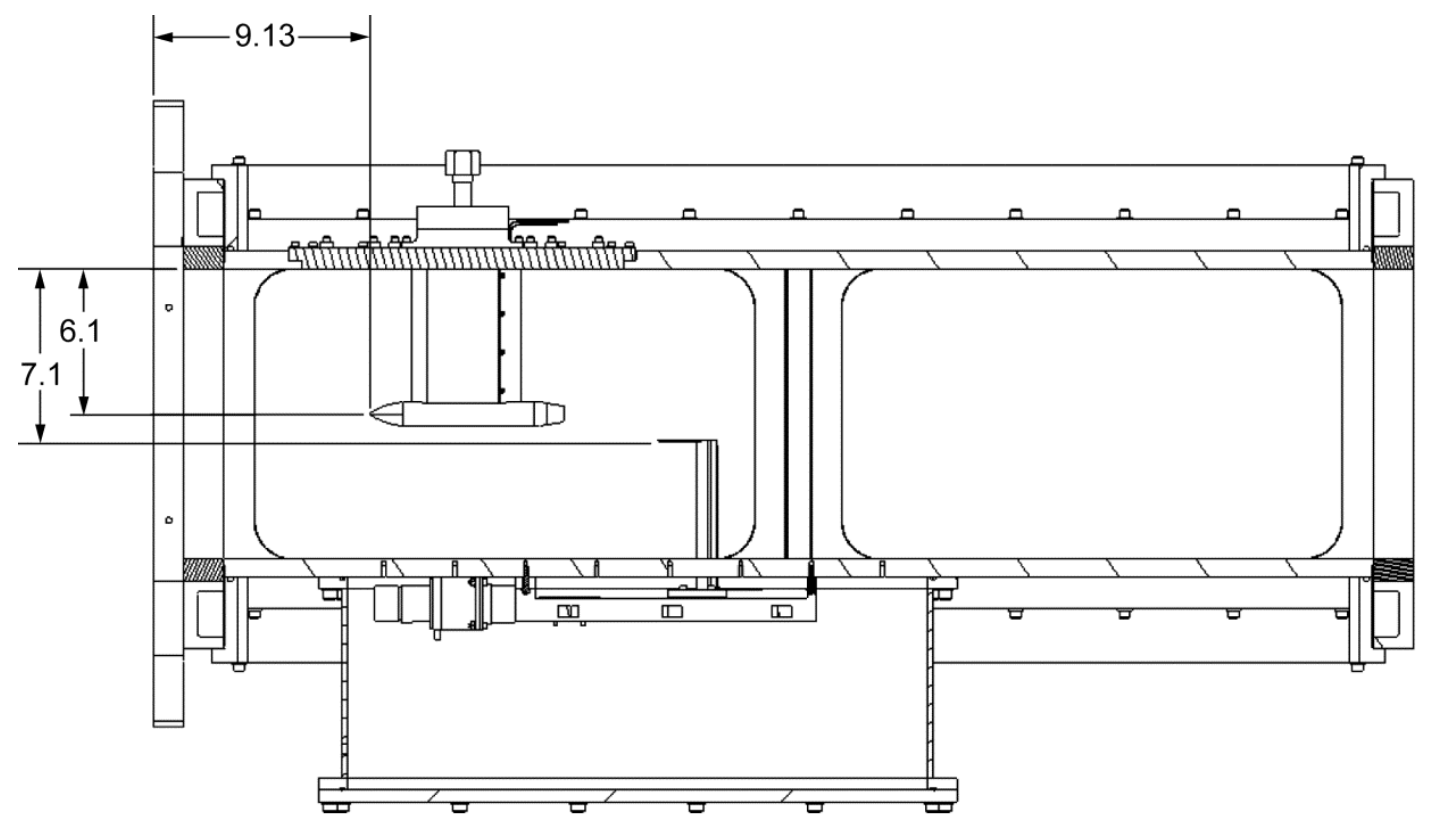

Figure 8.-Wind tunnel model cross section as installed in the 1- by 1-ft SWT test section.

\section{Instrumentation}

Instrumentation was located internally to measure NPR, and was limited to one total pressure probe upstream within the test nozzle, located on centerline, and one static pressure tap. There were two problems with the internal total pressure probe. First, the location was too close to the air supply passages in the strut, and the measurement was unsteady. Second, the internal total pressure probe was fragile and failed, thus the nozzle inlet instrumentation was replaced with a calculation of the NPR, based on mass flow measurement and nozzle throat diameter. Sonic flow equations for a venturi were used from Blevins (Ref. 9) to perform this calculation. An external static pressure probe was designed to survey near-field static pressure profiles at one nozzle diameter above the rig centerline. The static pressure probe was mounted on an airfoil probe support, and a sliding ball screw actuator, from the opposite side of the tunnel. The probe passed through the tunnel sidewall and the actuator was installed in an enclosure to match the tunnel pressure. The overall assembly, showing the probe location, is provided in Figure 8.

The static pressure probe had a capability to travel axially $8.4 \mathrm{in}$. to capture pressure profiles, starting 1.6 in. upstream of the nozzle exit, and extending downstream to where the plume interacts with the tunnel/wall shock reflection. Two static pressure probes were built, a conventional and a short design, based on Pinckney (Ref. 7). The conventional probe design, in Figure 9, had difficulty capturing shock waves. This difficulty was caused by the long distance between the probe tip and the static pressure 
measurement ports, where the measurement was not in the same flow environment as the probe tip. The short probe design, Figure 10, had less sensitivity to angle of attack, while achieving similar relaxation of static pressure at the location of the measurement ports. These probes were mounted on a 3/8 in. thick airfoil strut, allowing 5.625 in. of probe length between the static pressure holes and the airfoil support. For all experimental results presented, the shorter probe was used.

The model was placed between two transparent sidewalls in the 1- by 1-ft SWT for schlieren photography. Schlieren images were compared to Mach number contours generated by CFD analysis.

\section{Model Location}

The location of the model in the wind tunnel was a concern. Correct model location provided a clean nozzle flow-field at the correct Mach number. The nozzle flow-field also had to be free of shock reflections and shock interactions. A schlieren image, Figure 11, was collected with the nozzle operating at an NPR of 8. Six types of shock waves were evident. It was a challenge to place the nozzle inside these shocks and provide a clean nozzle flow-field. Sources for shock waves in the tunnel were:

1. Wind tunnel nozzle block.

2. Nosecone tip.

3. Nosecone and strut interaction.

4. Tunnel wall reflections.

5. Strut leading edge.

6. Nozzle plume (shock of interest).

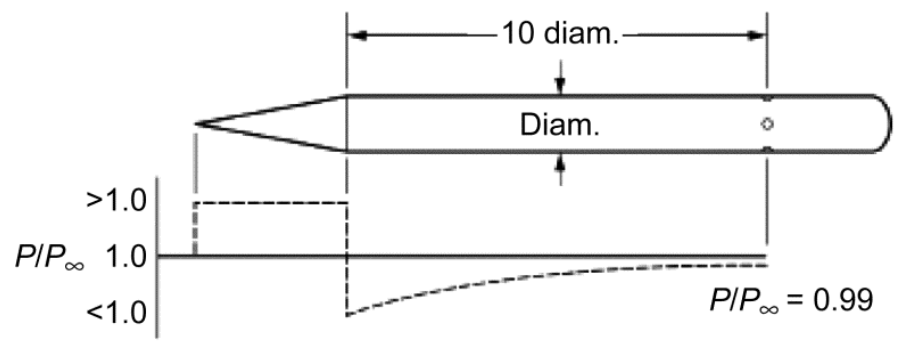

Figure 9.-Conventional static pressure probe (Ref. 7).

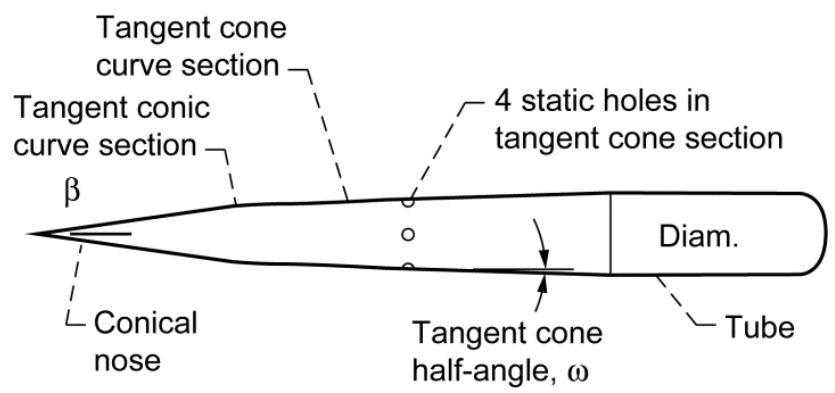

Figure 10.-Short static pressure probe design (Ref. 7). 


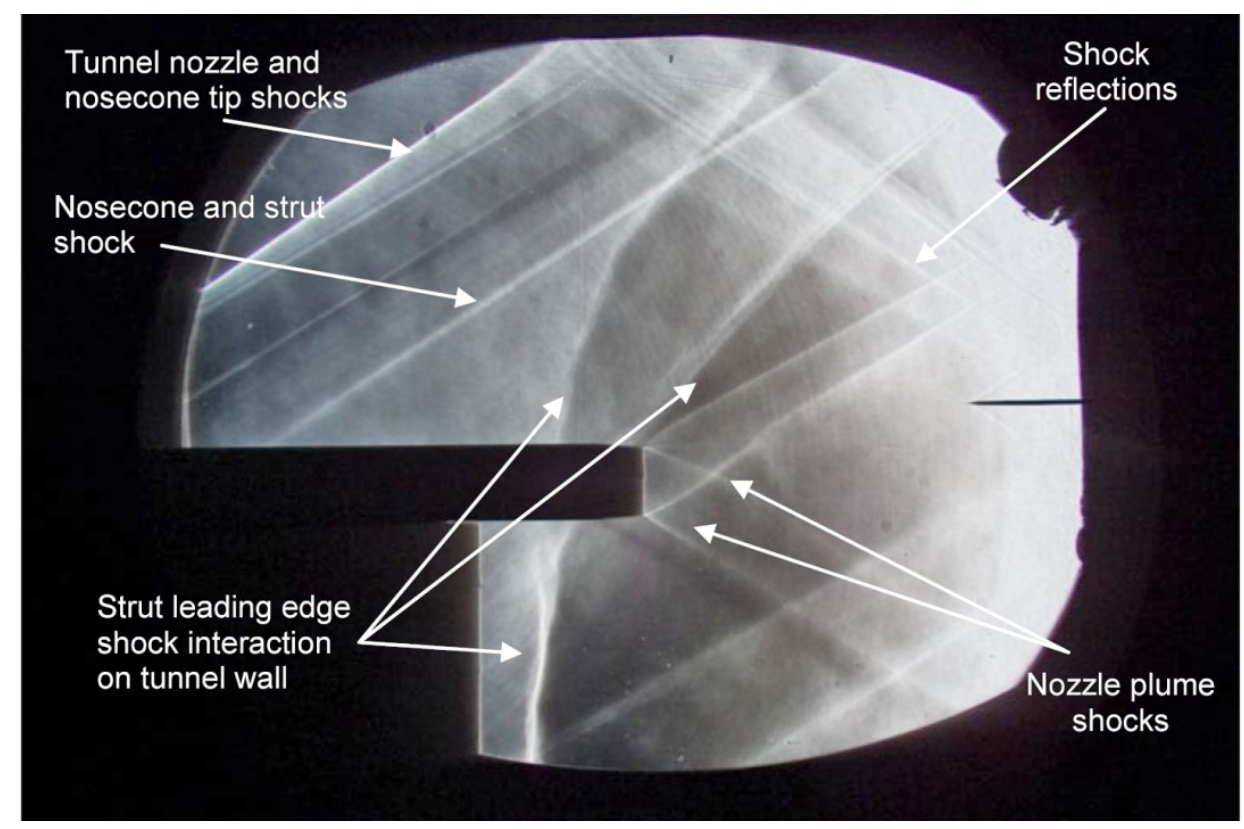

Figure 11.-Schlieren image of tunnel shock structure.

The shock wave from the wind tunnel nozzle block was generated by a small step in the tunnel wall. This step was located at the end of the interchangeable wind tunnel throat block and the shock wave from the nosecone tip was co-located with the wind tunnel nozzle block shock. Shock waves from the nosecone and strut interaction were fixed by strut geometry. This model design was kept as short as possible to avoid the wind tunnel wall reflections. The strut leading edge shock wave was a lateral shock wave that impacted the wind tunnel walls in a plane that appeared to interfere with the nozzle exhaust. However, the placement of this shock interaction was really on the wind tunnel wall, 6 in. away from the nozzle plume. This was validated by pre-test calculations and flow visualization, presented in Figures 12(a) and (b). Finally, the nozzle plume shock structure is visible, which was the objective of the experiment.

To validate the interaction of the model strut shock wave with the wind tunnel glass sidewall, flow visualization was performed with a fluorescent paint and oil mixture. Results indicated clean flow on the sidewall, except where a half-span shock from the support strut impinged on the glass sidewall. The oil and paint mixture, located on the wind tunnel walls, showed axial streaking up to the shock reflection, visible on the left side of Figure 12(a). At this point, the paint was removed from the sidewall by the shock interaction with the thick boundary layer on the tunnel wall, which caused flow separation and resulted in the oil pattern. Figure 12(b). also shows the shock wave pattern on the model strut and nosecone, and validated the presence of the nosecone and strut interaction shock wave.

As a final validation, the static pressure survey probe was replaced with a pitot probe. This probe was placed $1 \mathrm{in}$. away from the test nozzle centerline, and 1.63 in. upstream of the nozzle exit lip. Local pitot pressure and local static pressure were measured with the probes during two separate wind tunnel runs and used to compute a local Mach number. The local Mach number at this location was 1.956, which was very close to the tunnel set point of Mach 1.96. 

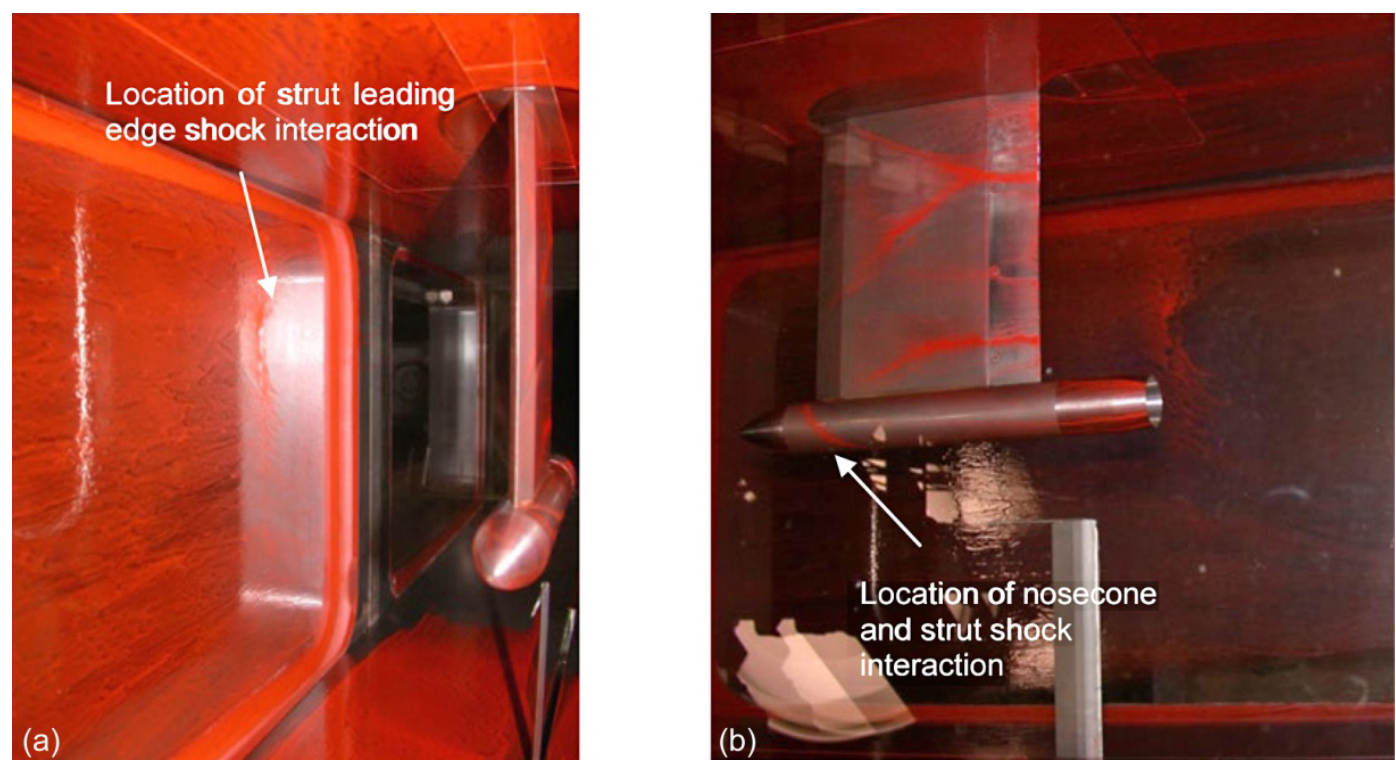

Figure 12.-(a) Oil flow visualization photo; view from upstream showing shock footprint on side wall. (b) Oil flow visualization photo; side view showing shock footprint on the strut.

\section{Results}

This section compares results from pre-test CFD predictions with the experimental results from the GRC 1-ft by 1-ft Supersonic Wind Tunnel. Comparisons include schlieren images, CFD contour plots (Mach number), and static pressure surveys at one nozzle-diameter above the nozzle

\section{Near-Field CFD Results}

Pre-test CFD results were obtained with a two-dimensional model of 'Nozzle 6' from Putnam and Capone (Ref. 3). Detailed CFD results are presented in Castner(Ref. 5), and included the $\triangle P / P$ at 150 in. away from the nozzle centerline. The previous Figure 5(a) shows the pressure signature results at $150 \mathrm{in}$. away, and were considered far-field results for this discussion. In the far-field, pressure signatures were provided for NPRs from 6 to 10. All the signatures have the same characteristic. The first reduction in pressure is the expansion off the nozzle boat-tail. This is followed by a shock at the nozzle lip, which is then followed by a secondary expansion and shock off the nozzle exhaust plume. The first reduction in pressure, caused by nozzle boat-tail expansion, is cut short by the shock at the nozzle lip as NPR is increased from 6 to 10 .

Near-field CFD results are shown in Figure 13. Comparisons with wind tunnel data were not possible at a location $150 \mathrm{in}$. away from the nozzle, given the 1- by 1-ft wind tunnel cross section. Comparisons were made with near-field static pressure surveys, which were performed at one nozzle diameter above the nozzle centerline, on the side opposite the model support strut. From the CFD, the near-field pressure pattern consisted of an expansion from the nozzle boat-tail, followed by a strong shock at the nozzle lip. In the near-field, the nozzle lip shock appeared to dominate the pressure signature as NPR was increased from 6 to 10. As NPR was increased the location of the nozzle lip shock moved a small amount and the shock strength increased. Also, the stronger lip shock caused a weaker secondary expansion and shock around the nozzle plume.

Figure 14(a) shows a color contour plot of Mach number for the CFD solution. In this plot, the boat-tail expansion, nozzle lip shock, plume expansion and plume shock are visible. If the nozzle lip shock was observed far from the nozzle, the location of the shock changed with NPR. This can be seen from Figure 14(b) and (c). The location of the nozzle lip shock at NPR 6 is highlighted, and then superimposed on the contour plot for NPR 10. In this manner the change in nozzle lip shock location can be demonstrated. 


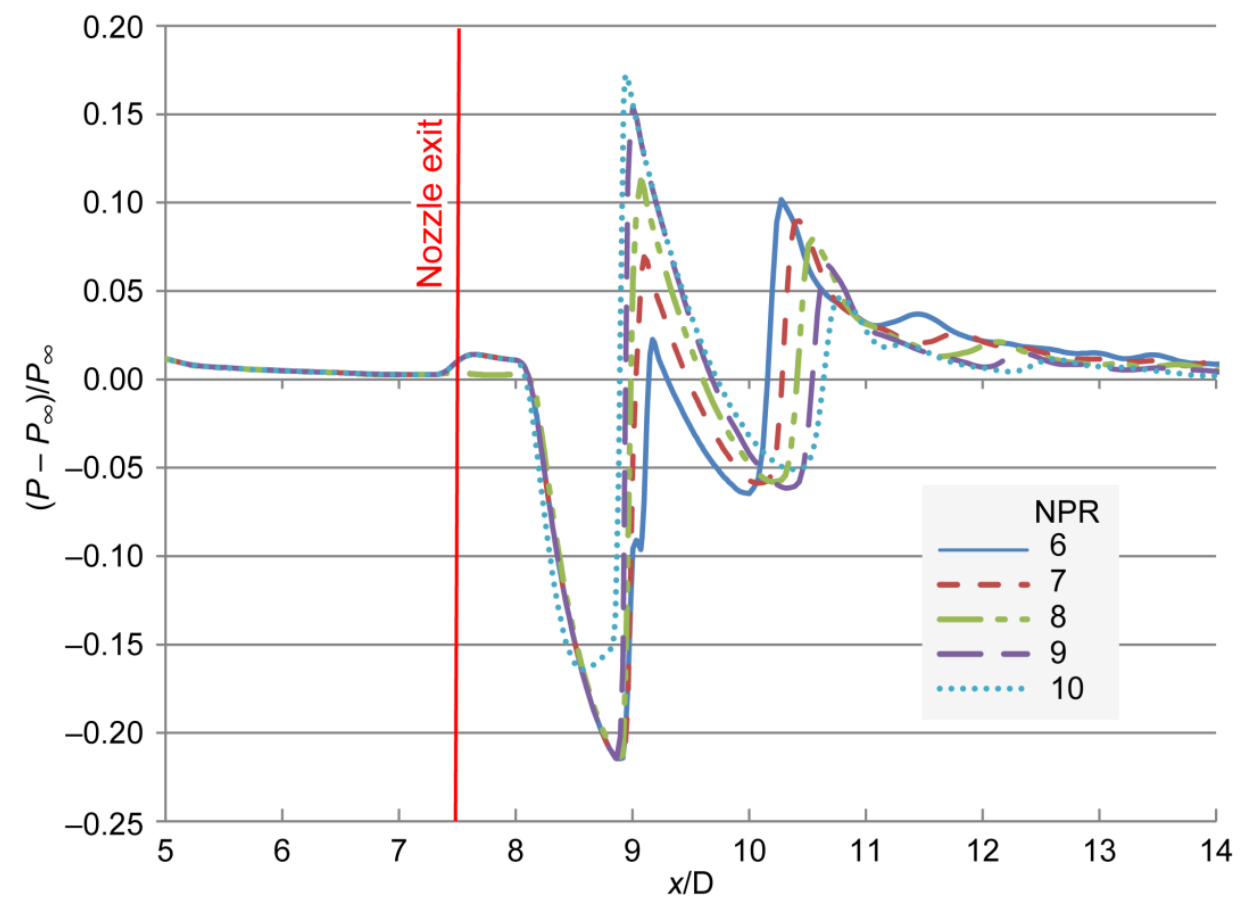

Figure 13.-Predicted Near-filed pressure profiles $\Delta P / P_{\infty}$ at $y=1.0$ in from nozzle centerline. Baseline 'Nozzle 6' NPR 6 to 10, Mach 2.2.

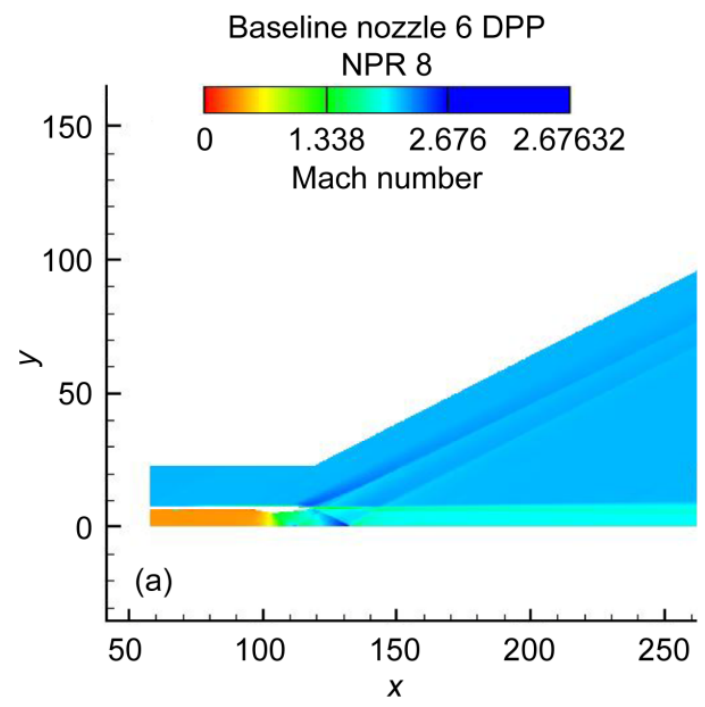

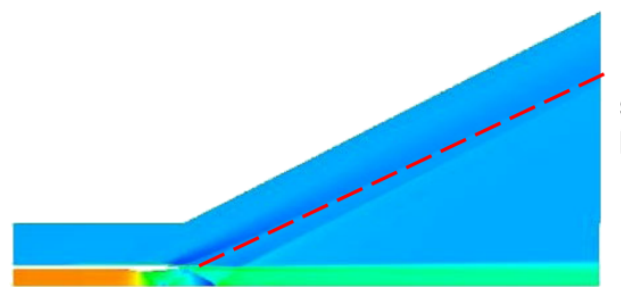

(b)

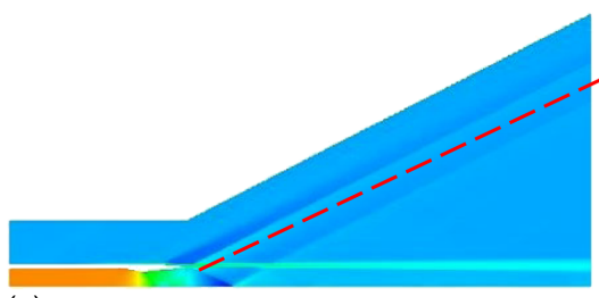

(c)
Difference in nozzle lip shock location between NPR 6 and NPR 10

Figure 14.-(a) 'Nozzle 6' CFD Mach Number Contour NPR 8. (b) 'Nozzle 6' CFD Mach Number Contour NPR 6. (c) 'Nozzle 6' CFD Mach Number Contour NPR 10. 
The angle of the nozzle lip shock increased with respect to the nozzle centerline. When observed at the measurement location, the nozzle lip shock moved forward and suppressed the nozzle boat-tail expansion, and caused a corresponding reduction in the boat-tail expansion, and a favorable change in the observed pressure signature. A reduction in boat-tail expansion could be exploited to reduce the right hand portion of the sonic boom $\mathrm{N}$-wave, thereby reducing sonic boom signature.

\section{Near-Field Experimental Results}

In the 1- by 1-ft Supersonic Wind Tunnel, the experimental pressure signatures were measured at one-diameter away from the 'Nozzle 6' centerline, collected on the side opposite the model support strut. Data were collected at this location due to space restrictions, as far-field data at $150 \mathrm{in}$. away was not possible in a small wind tunnel. Experimental pressure signatures $\left(\Delta P / P_{\infty}\right)$ were collected over a 6 in. axial distance at 0.1 in. increments, and are in shown in Figure 16. The same pressure pattern was present and consisted of an expansion from the nozzle boat-tail, followed by a strong shock at the nozzle lip. In the near-field, the nozzle lip shock appeared to dominate the pressure signature as NPR was increased from 6 to 10. The location of the nozzle lip shock moved a small amount as NPR was increased and the shock strength increased as NPR was increased. Also, in cases with a stronger lip shock, a weaker secondary expansion and shock around the nozzle plume was observed.

Comparisons to the previous CFD results show that the trends in the experimental data were the same as computational results; however, the values were different. For example, the following comparisons were taken from data at NPR 8: for the boat-tail expansion the minimum $\triangle P / P_{\infty}$ value from CFD was -0.209 while the minimum experimental value was -0.172 . For the nozzle lip shock the CFD value was 0.118 while the experimental value was -0.018 . The trend in the experimental data was the same as the CFD, where increasing levels of NPR provided a stronger nozzle lip shock and would provide the same results if the shock waves could propagate to the far-field. The stronger nozzle lip shock at high NPR would again intersect the boat-tail expansion earlier and suppress the expansion wave. Evidence of the movement of the nozzle lip shock can be seen in the pressure signatures in Figure 15, and also in the schlieren images. The data for the NPR of 13 was skipped to save time during the experiment.

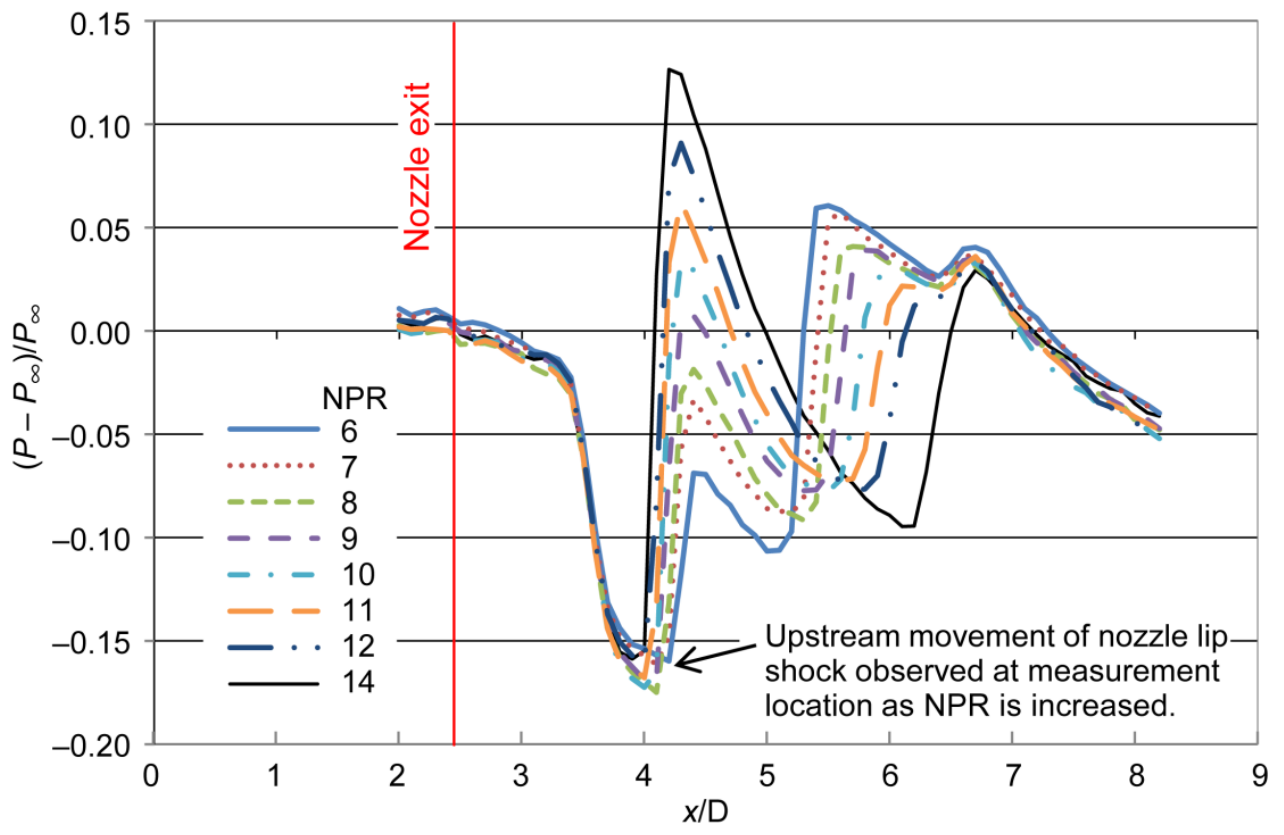

Figure 15.-Experimental results, 'Nozzle 6' $\Delta P / P$, Mach 1.96. 
(a)
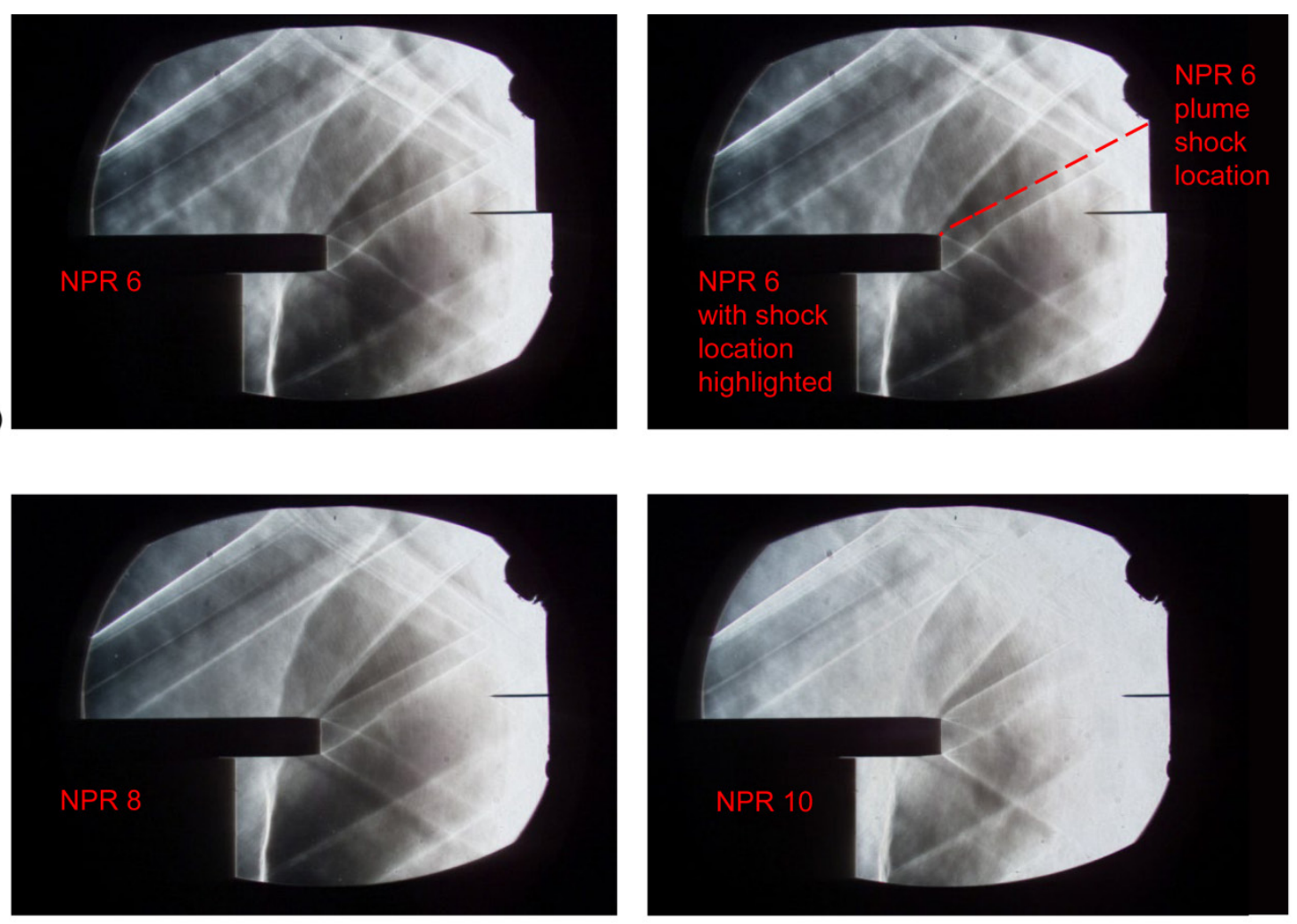

(b)
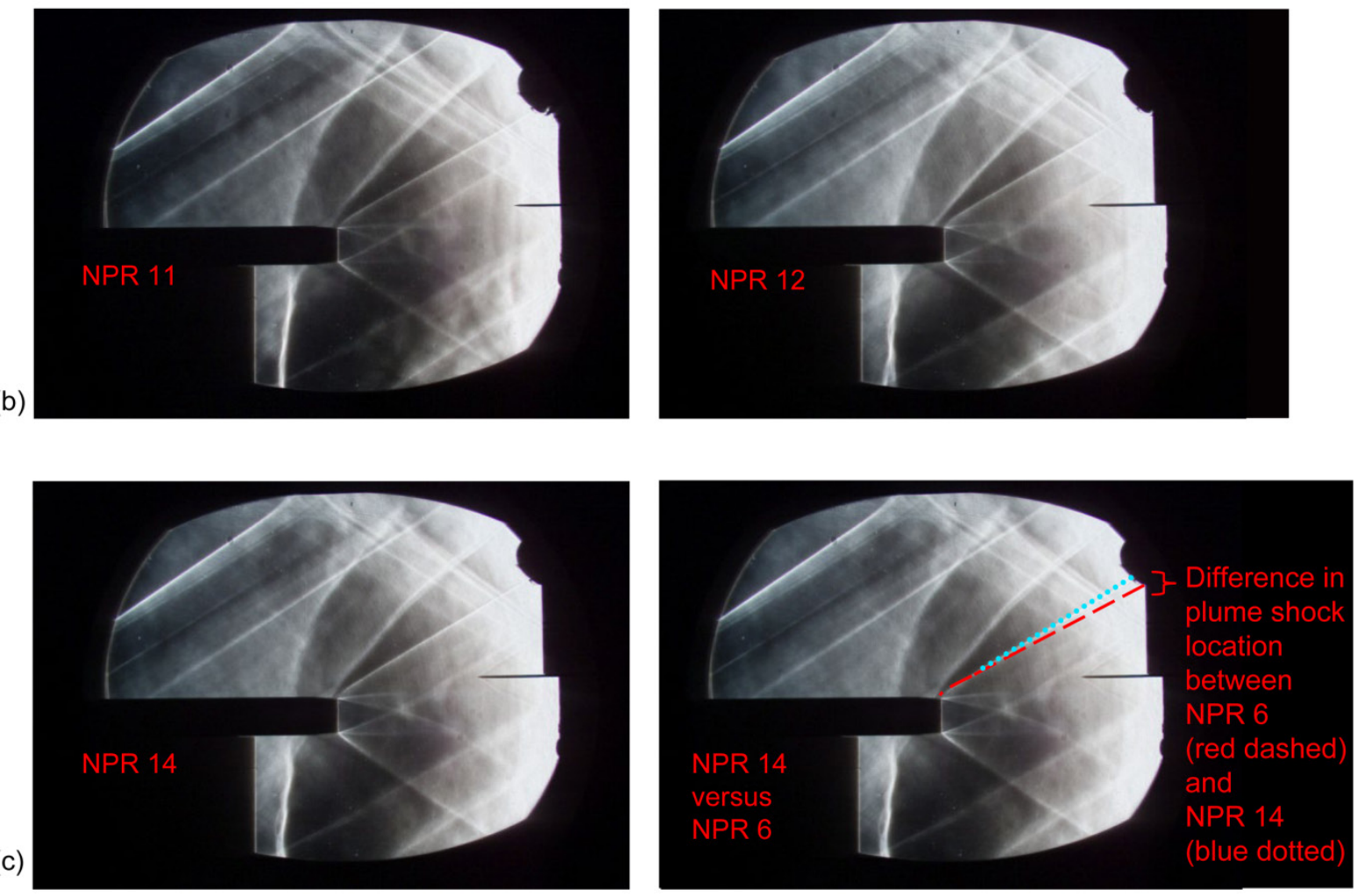

Figure 16.-(a) Schlieren images of plume for NPR 6. (b) Sample schlieren images of plume for NPR 8, 10, 11 and 12. (c) Schlieren images of plume for NPR 14 
Schlieren images are shown in Figure 16, and also demonstrate the same flow features as presented in CFD contour plots of Mach number. A description of the extra shock structures seen in the images was provided in a previous section. In the schlieren images, the following flow features can be observed: (1) the expansion wave from the nozzle boat-tail, (2) the shock at the nozzle lip, (3) the secondary expansion from the nozzle plume, and (4) the secondary shock from the nozzle plume. Figure 16 illustrates how the shock location moves with NPR. For an NPR of 6, the location of the nozzle lip shock was highlighted in Figure 16(a). The shock location from the NPR 6 plume was superimposed on the schlieren image for an NPR of 14 (Fig. 16(c)) and demonstrates the location of the lip shock moved upstream. In the near-field, the change is subtle, but becomes noticeable at greater distances from the nozzle.

If these shock waves for the under-expanded nozzle cases, greater than NPR=8, were allowed to propagate to the far-field the effect would be a reduction in peak-to-peak pressure differential. In practice, creating under-expanded flow can be achieved with increasing nozzle pressure or changing divergent section geometry (Stitt (Ref. 8)). The shock from the nozzle lip suppresses the nozzle boat-tail expansion and a reduction in expansion could improve the right hand portion of the sonic boom signature. From previous studies (Castner (Ref. 5)), the thrust coefficient of 'Nozzle 6' ranged from 0.98 at NPR of 6 to 0.991 at NPR of 10, resulting in reasonable nozzle performance.

\section{Differences Between CFD and Experimental Results}

Differences between the CFD results and the experimental results were evident in the schlieren images. Close examination shows that the shock wave from the nozzle lip was anchored at the nozzle lip, but curved away from the nozzle, see Figure 17. When observed at the measurement plane, this curvature caused the location of the nozzle lip shock to change, and intersect the nozzle boat-tail expansion earlier than in the CFD results. In computational predictions, the shock wave formed off of the nozzle lip with no curvature. It was also evident in the schlieren images that the shock waves from the top of the nozzle and the bottom of the nozzle were not the same. The cause for the change in shape for the nozzle lip shock appears to be deflection of the jet plume, due to influence of the wind tunnel model support strut. This can also be seen in Figure 18 as the shock diamond in the nozzle plume is not on nozzle centerline.

The deflection of the jet plume was viewed in the schlieren images, and was also validated with posttest CFD analysis, provided in Figure 18 and 19. Post-test CFD included a three-dimensional model of the entire wind tunnel model at the proper model scale, while pre-test CFD was performed on an axisymmetric model which did not include the nosecone or strut. Levels of pressure profiles from the three-dimensional CFD analysis did not match the experimental results, see Figure 19. The boat tail expansion was captured well, but the strength of the nozzle lip shock was stronger in three-dimensional CFD than in the experiment.

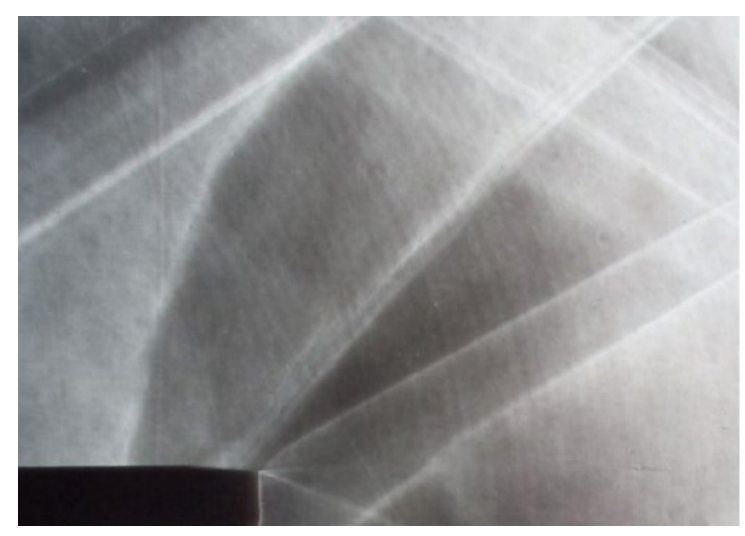

Figure 17.-Schlieren image showing curvature of nozzle lip shock, NPR of 8. 


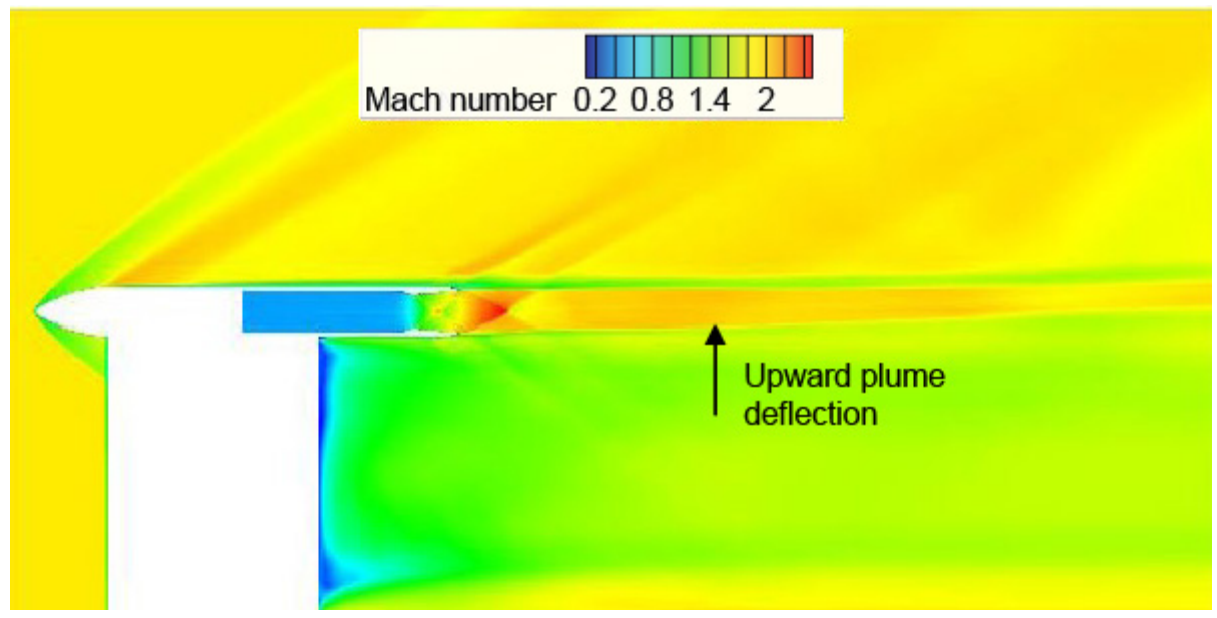

Figure 18.-Three-dimensional CFD analysis results: Mach number contour.

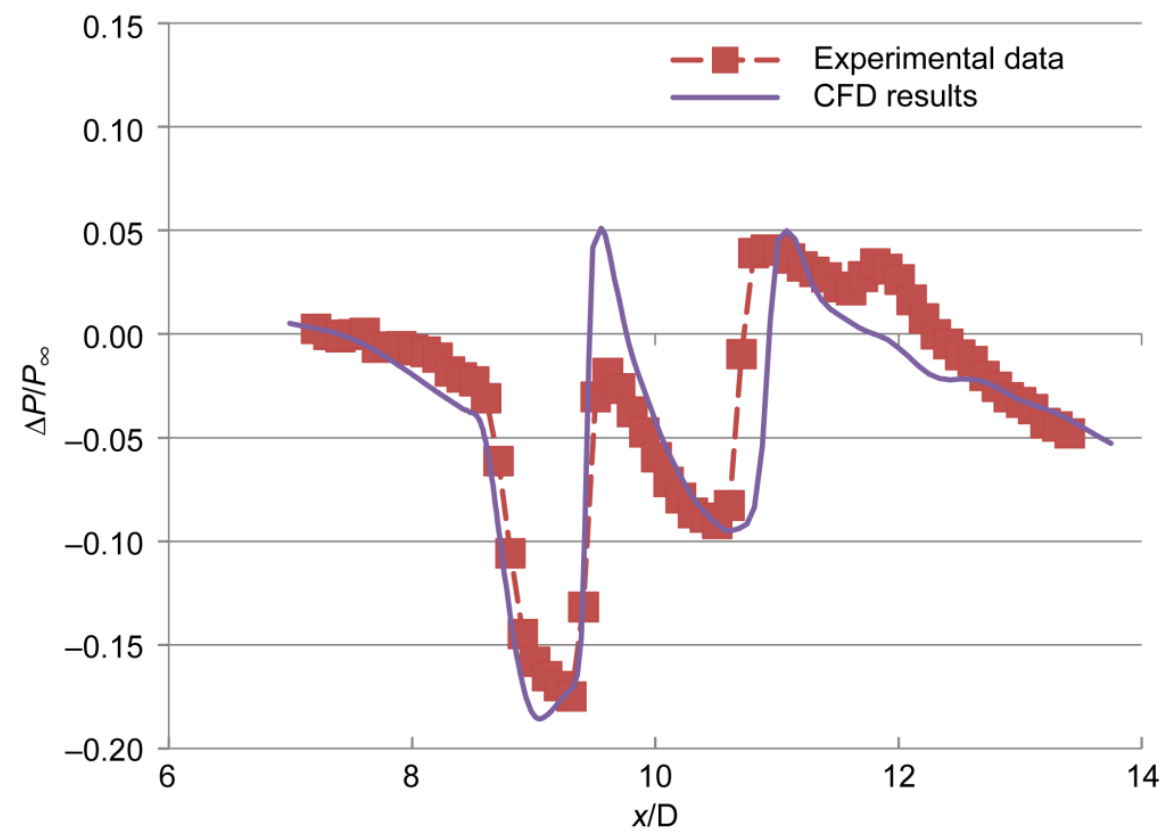

Figure 19.--'Nozzle 6' Comparison of three-dimensional CFD analysis to experimental data at NPR of 8.

Despite these issues, use of this model in the 1- by 1-ft SWT did demonstrate the main effects of the nozzle plume structure, and validated how the nozzle boat-tail expansion is reduced by the shock at the nozzle lip.

\section{Conclusions}

Background was provided on a baseline nozzle used to study nozzle plume effects on sonic boom. Previous CFD analysis showed how the shock wave was formed at the nozzle lip and interacted with the nozzle boat-tail expansion wave.

An experiment was designed and conducted in the 1-ft by 1-ft Supersonic Wind Tunnel to validate the computational study. The wind tunnel model consisted of a test nozzle supported by an upper plenum and strut. Instrumentation allowed measurement of NPR and near-field static pressure, presented as 
$\Delta P / P_{\infty}$. Schlieren images and flow visualization were used to validate proper placement of the model in the wind tunnel to avoid shock reflections and provide for a clean nozzle flow-field.

Pre-test axisymmetric CFD results were presented at one-diameter above the test nozzle centerline, as it was not possible to get far-field pressure data in a small wind tunnel. Results show how the nozzle lip shock moved with increasing NPR and reduced the nozzle boat-tail expansion, causing a favorable change in the observed pressure signature.

Experimental results were presented for comparison to the CFD results. Experimental pressure signatures at one-diameter above the nozzle centerline were consistent with the pressure signatures from analysis, however, the values were different. The strong nozzle lip shock at high values of NPR intersect the nozzle boat-tail expansion and suppress the expansion wave.

Differences between the pre-test CFD and the experiment were studied with a post-test threedimensional CFD analysis. The main cause of the differences was attributed to the curvature of the shock wave from the nozzle lip observed at the top of the nozzle in experimental results. This curvature resulted in a change in the location of the nozzle lip shock when compared to analysis. The change in the shape of the lip shock was caused by upward deflection of the nozzle plume, which was visible in the threedimensional CFD and the schlieren photos from the experiment. The curved shock wave intersected the nozzle boat-tail expansion earlier and caused additional suppression of the boat-tail expansion.

In this experiment, under-expanded nozzle flow was achieved by increasing NPR. Under-expanded nozzle flow can also be achieved through changes in divergent section geometry. The shock from the nozzle lip suppresses the boat-tail expansion, and increasing under-expanded flow causes stronger shock waves at an increased angle with respect to the nozzle centerline. The increased shock angle causes increased suppression of the flow expansion around the external boat-tail geometry. A reduction in the expansion can decrease the magnitude of the right hand portion of the sonic boom signature. The results also suggest that a future study on exhaust nozzle vector angle may be of interest to the sonic boom community.

The present analysis and experiment developed a set of consistent trends that demonstrate the feasibility of modifying the right hand portion of the sonic boom $\mathrm{N}$-wave caused by the boat-tail expansion, through a change in nozzle pressure or divergent section geometry.

\section{References}

1. Graham, D., et al.: Aerodynamic Design of Shaped Sonic Boom Demonstration Aircraft. AIAA 2005-0009, 2005.

2. Freund, D., et al.: Quiet Spike Prototype Aerodynamic Characteristics From Flight Test. AIAA 2008-125, 2005.

3. Putnam, L. and Capone, F.: Experimental Determination of Equivalent Solid Bodies to Represent Jets Exhausting into a Mach 2.20 External Stream, NASA TN-D-5553.

4. Barger, R. L. and Melson, N. D.: Comparison of Jet Plume Shape Predictions and Plume Influence on Sonic Boom Signature, NASA TP-3172.

5. Castner, R. S.: Analysis of Plume Effects on Sonic Boom Signature for Isolated Nozzle Configurations, NASA/TM-2008-215414.

6. Soeder, R., Stark. D., Leone, J., and Henry, M.: NASA Glenn 1- by 1- Foot Supersonic Wind Tunnel User Manual, NASA/TM-1999-208478.

7. Pinckney, S. Z.: A Short Static Pressure Probe Design for Supersonic Flow, NASA TN D-7978.

8. Stitt, L. E.: Exhaust Nozzles for Propulsion Systems with Emphasis on Supersonic Cruise Aircraft, NASA RP-1235.

9. Blevins, R. D.: Applied Fluid Dynamics Handbook, Krieger, Florida, 1992 pp. 126-135. 



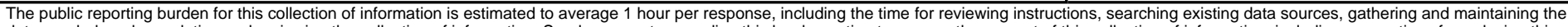

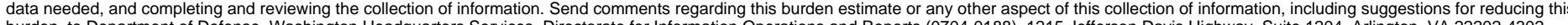

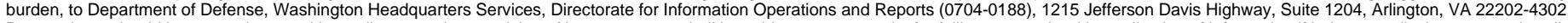

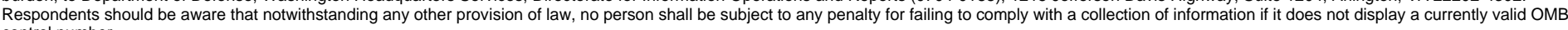

control number.
PLEASE DO NOT RETURN YOUR FORM TO THE ABOVE ADDRESS.

\begin{tabular}{l|l|l}
$\begin{array}{l}\text { 1. REPORT DATE (DD-MM-YYYY) } \\
01-12-2011\end{array}$ & $\begin{array}{l}\text { 2. REPORT TYPE } \\
\text { Technical Memorandum }\end{array}$ & 3. DATES COVERED (FrOm - To) \\
\hline
\end{tabular}

4. TITLE AND SUBTITLE

Exhaust Nozzle Plume Effects on Sonic Boom Test Results for Isolated Nozzles

5a. CONTRACT NUMBER

5b. GRANT NUMBER

5c. PROGRAM ELEMENT NUMBER

6. AUTHOR(S)

Castner, Raymond, S.

\section{5d. PROJECT NUMBER}

5e. TASK NUMBER

5f. WORK UNIT NUMBER

WBS 984754.02.07.03.13.05

7. PERFORMING ORGANIZATION NAME(S) AND ADDRESS(ES)

National Aeronautics and Space Administration

John H. Glenn Research Center at Lewis Field

Cleveland, Ohio 44135-3191

\section{SPONSORING/MONITORING AGENCY NAME(S) AND ADDRESS(ES)}

National Aeronautics and Space Administration

Washington, DC 20546-0001
8. PERFORMING ORGANIZATION

E-17430 REPORT NUMBER

\section{DISTRIBUTIONIAVAILABILITY STATEMENT}

Unclassified-Unlimited

Subject Categories: 01 and 07

Available electronically at http://www.sti.nasa.gov

This publication is available from the NASA Center for AeroSpace Information, 443-757-5802

\section{SUPPLEMENTARY NOTES}

\section{ABSTRACT}

Reducing or eliminating the operational restrictions of supersonic aircraft over populated areas has led to extensive research at NASA. Restrictions were due to the disturbance of the sonic boom, caused by the coalescence of shock waves formed off the aircraft. Recent work has been performed to reduce the magnitude of the sonic boom $\mathrm{N}$-wave generated by airplane components with focus on shock waves caused by the exhaust nozzle plume. Previous Computational Fluid Dynamics (CFD) analysis showed how the shock wave formed at the nozzle lip interacts with the nozzle boat-tail expansion wave. An experiment was conducted in the 1-by 1-ft Supersonic Wind Tunnel at the NASA Glenn Research Center to validate the computational study. Results demonstrated how the nozzle lip shock moved with increasing nozzle pressure ratio (NPR) and reduced the nozzle boat-tail expansion, causing a favorable change in the observed pressure signature. Experimental results were presented for comparison to the CFD results. The strong nozzle lip shock at high values of NPR intersected the nozzle boat-tail expansion and suppressed the expansion wave. Based on these results, it may be feasible to reduce the boat-tail expansion for a future supersonic aircraft with under-expanded nozzle exhaust flow by modifying nozzle pressure or nozzle divergent section geometry.

\section{SUBJECT TERMS}

Exhaust; Nozzle; Plume; Wing; Sonic boom

\begin{tabular}{|c|c|c|c|c|c|}
\hline \multicolumn{3}{|c|}{ 16. SECURITY CLASSIFICATION OF: } & \multirow{2}{*}{$\begin{array}{l}\text { 17. LIMITATION OF } \\
\text { ABSTRACT } \\
\text { UU }\end{array}$} & \multirow{2}{*}{$\begin{array}{l}\text { 18. NUMBER } \\
\text { OF } \\
\text { PAGES } \\
24\end{array}$} & \multirow{2}{*}{$\begin{array}{l}\text { 19a. NAME OF RESPONSIBLE PERSON } \\
\text { STI Help Desk (email:help@sti.nasa.gov) } \\
\text { 19b. TELEPHONE NUMBER (include area code) } \\
\text { 443-757-5802 }\end{array}$} \\
\hline $\begin{array}{l}\text { a. REPORT } \\
U\end{array}$ & $\begin{array}{l}\text { b. ABSTRACT } \\
U\end{array}$ & $\begin{array}{l}\text { c. THIS } \\
\text { PAGE } \\
\text { U }\end{array}$ & & & \\
\hline
\end{tabular}



